\title{
Synergetic Control of Grid-Connected Photovoltaic Systems
}

\author{
Junjie Qian, Kaiting Li, Huaren Wu, Jianfei Yang, and Xiaohui Li \\ School of Electrical and Automation Engineering, Nanjing Normal University, Nanjing 210042, China \\ Correspondence should be addressed to Xiaohui Li; 61011@njnu.edu.cn
}

Received 8 October 2016; Revised 26 November 2016; Accepted 16 January 2017; Published 29 March 2017

Academic Editor: Md. Rabiul Islam

Copyright (c) 2017 Junjie Qian et al. This is an open access article distributed under the Creative Commons Attribution License, which permits unrestricted use, distribution, and reproduction in any medium, provided the original work is properly cited.

\begin{abstract}
It is important to improve the dynamic performance and the low-voltage ride-through (LVRT) capability of a grid-connected photovoltaic (PV) system. This paper presents synergetic control for the control of a grid-connected PV system. Modeling of a grid-connected PV system is described, and differential-algebra equations are obtained. Two control strategies are used in normal operation and during LVRT of a PV system. Practical synergetic controllers with two control strategies are synthesized. The mathematical expressions are derived for computing control variables. The design of the synergetic controllers does not require the linearization of the grid-connected PV system. A grid-connected PV system with synergetic controllers is simulated in Simulink surroundings. The control performance is studied in normal operation and during LVRT. Simulation results show that the synergetic controllers are robust and have good dynamic characteristics under different operation states.
\end{abstract}

\section{Introduction}

The world is faced with serious problems of energy depletion and environmental pollution. The research and development of photovoltaic (PV) technologies have become a hot topic in the world [1]. Solar PV is now used around the world as an important technology for the conversion of solar energy because of its cleanliness and security. The solar PV capacity increased $25 \%$ over 2014 to a record $50 \mathrm{GW}$, lifting the global total to $227 \mathrm{GW}$. The solar PV industry is one of the fastest growing high-tech industries [2].

The control of a PV system is an important and difficult task. A grid-connected PV system mainly includes maximum power point tracking (MPPT) and the control of the DC-AC converter. Much research on MPPT has been conducted, and various MPPT algorithms have been proposed. The maximum power point (MPP) may be located by the perturbation and observation ( $\mathrm{P} \& \mathrm{O})$ algorithms [3], the incremental conductance (InC) algorithm [4], and the artificial neural network algorithm [5].

Reference [6] proposes a modified InC algorithm. The algorithm eliminates the division calculations involved in its structure and improves the variable step size, which only depends on the PV power change. Reference [7] improves $\mathrm{P} \& \mathrm{O}$ algorithm. This approach combines ant colony optimization with the traditional $\mathrm{P} \& \mathrm{O}$ method to yield faster and efficient convergence. This improved $\mathrm{P} \& \mathrm{O}$ algorithm can recognize global MPP under partially shaded conditions. A new MPPT algorithm is proposed in [8]. This scheme uses a gray wolf optimization technique to track the global peak of a PV array under partial shading conditions. It can solve the problems such as lower tracking efficiency, steady-state oscillations, and transients as encountered in $\mathrm{P} \& \mathrm{O}$.

A two-stage three-phase grid-connected PV system in [9] contains a DC-DC boost converter and a DC-AC VSC converter. Pulse width modulator (PWM) signals fire the converters. The DC-AC VSC control system has an external voltage control loop and an internal current control loop. The external control loop regulates the DC link voltage, and the internal control loop regulates grid currents. The grid currents are transformed into $d$-axis and $q$-axis currents to accomplish vector control. Two control loops adopt the proportional-integral (PI) algorithm. Reference [10] presents a novel sliding-mode (SM) control for grid-connected PV systems. A systematic adaptive procedure to calculate the band of the hysteresis comparators is developed to improve the performance of the SM controller. A vector controller can keep the maximum power delivery of the PV system. Reference [11] uses a probabilistic wavelet fuzzy neural 
network (PWFNN) to structure the reactive power controller for a grid-connected PV system. The balance of the active power between the PV array and the DC-AC converter during grid faults is controlled by the DC link voltage. The controller can improve the operation of the grid-connected PV system during LVRT. Reference [12] suggests injecting the maximum rated current to maximize the inverter power capability during LVRT. The strategy combines a proper balance between positive- and negative-current sequences. High- and low-power production scenarios limit the inverter output current to the maximum rated value and avoid active power oscillations. Reference [13] presents a new adaptive PI controller using the continuous mixed p-norm (CMPN) algorithm for enhancing the LVRT capability of gridconnected PV systems. The adaptive PI controller is used to control the DC-AC converter. The gains of the PI controller are changed by the CMPN algorithm online without the need to fine-tune or optimize.

Reference [14] reviews the general synergetic control design procedure. Synergetic control is applied to a DC-DC boost converter, deriving a basic control law. An adaptive control strategy gives better trade-off between large-signal stability and load step response time. Reference [15] introduces a practical synergetic controller to regulate the buck converters that coordinate pulse current charging of batteries. Simulation and experiment results show that the synergetic controller is robust for such nonlinear dynamic systems and achieves better performance than the standard PI controller.

This paper presents a design for the synergetic controllers for an internal current control loop of a three-phase gridconnected PV system. The theory of synergetic control is first described. Modeling of a grid-connected PV system is introduced, and differential-algebra equations are obtained. Synergetic controllers are derived in detail for normal operation and during LVRT of a PV system. Two control strategies are used during normal and LVRT operations of PV systems. The design of a synergetic controller does not require linearization of the PV system. The parameters $T_{1}$ and $T_{2}$ of the two synergetic controllers are the same, and $T_{1}$ equals $T_{2}$. The parameters of the synergetic controllers are easy to determine, and the proposed control schemes are easy to achieve. An example given in Matlab is adapted according to the synergetic controllers for assessing the performance of synergetic control of the grid-connected PV system. The synergetic control is chatter-free, and the simulation results demonstrate the effectiveness of the proposed control schemes.

\section{Synergetic Control Theory}

Synergetic control is a state space control method based on modern mathematics. Synergetic control is applicable to the control of nonlinear, dynamic, and high-dimensional systems. It can be perfectly analyzed by mathematical expressions.

The nonlinear state equation of a controlled system is

$$
\dot{x}=f(x, u, t) \text {, }
$$

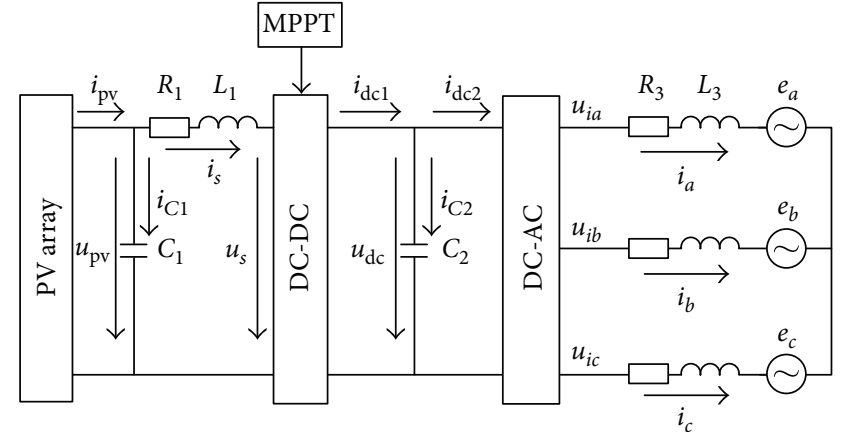

Figure 1: Main circuit of a grid-connected PV system.

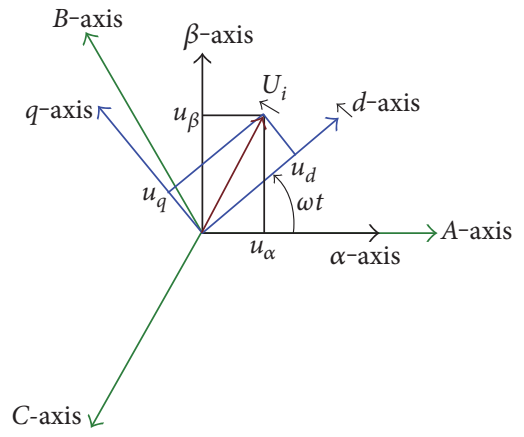

FIgURE 2: Reference frames.

where $x$ is the state vector of the controlled system $\Re^{n}, f(\cdot)$ is a continuous nonlinear function, and $u$ is the control vector of $\mathfrak{R}^{m}(m \leq n)$.

The macrovariables are defined for each input channel as a function of the state variables. The synergetic controller directs the system to move into the manifold from any initial motion point

$$
\psi(x, t)=0,
$$

where $\psi$ is the macrovector of $\mathfrak{R}^{k}(0<k \leq m)$.

The dynamic evolution of the macrovariable towards the manifolds is defined as follows [14]:

$$
T \dot{\psi}+\psi=0,
$$

where $T$ defines the rate of convergence of the system.

Substituting from (2) into (3) yields

$$
T \frac{\partial \psi}{\partial x} \dot{x}+\psi=0 .
$$

The control vector $u$ can be acquired by substituting (1) into (4). The system can be controlled to stay in the desired manifold.

\section{Modeling of the Grid-Connected PV System}

The main circuit of the two-stage grid-connected PV system is described in Figure 1. A PV array is connected to a power 


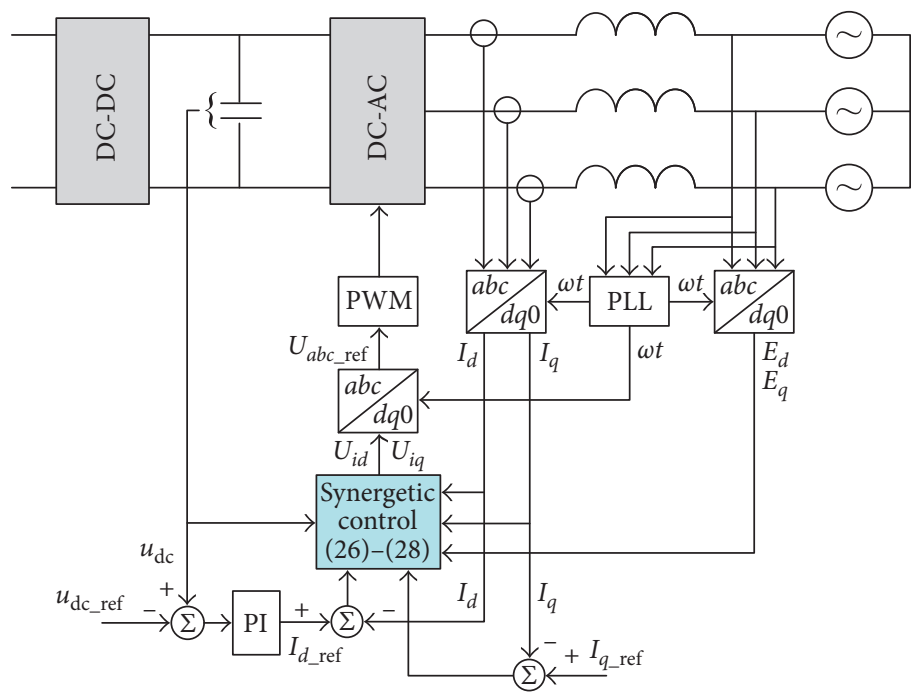

FIGURE 3: Synergetic control scheme of the PV system in normal operation.

grid via a DC boost converter and a three-phase voltage source converter (VSC) [9].

The differential equations (5), (6), (7), and (8) can be written according to Figure 1.

$$
\begin{aligned}
C_{1} \frac{d u_{\mathrm{pv}}}{d t} & =i_{\mathrm{pv}}-i_{s}, \\
u_{\mathrm{pv}} & =R_{1} i_{s}+L_{1} \frac{d i_{s}}{d t}+u_{s}, \\
C_{2} \frac{d u_{\mathrm{dc}}}{d t} & =i_{\mathrm{dc} 1}-i_{\mathrm{dc} 2}, \\
U_{i a b c}-E_{a b c} & =R_{3} I_{a b c}+L_{3} \frac{d I_{a b c}}{d t},
\end{aligned}
$$

where

$$
\begin{gathered}
U_{i a b c}=\left[\begin{array}{l}
u_{i a} \\
u_{i b} \\
u_{i c}
\end{array}\right], \\
E_{a b c}=\left[\begin{array}{l}
e_{a} \\
e_{b} \\
e_{c}
\end{array}\right], \\
I_{a b c}=\left[\begin{array}{l}
i_{a} \\
i_{b} \\
i_{c}
\end{array}\right],
\end{gathered}
$$

$E_{a b c}$ is the grid voltage, $U_{i a b c}$ is the output voltage of the DCAC VSC converter, and $I_{a b c}$ is the alternating current.

Equation (8) is based on a three-phase (abc) reference frame. $a b c, \alpha \beta 0$, and $d q 0$ reference frames are shown in Figure 2 [16].

Equation (8) is transformed into (10) from the $a b c$ reference frame to the $d q 0$ rotating reference frame using the sinus-based Park transformation.

$$
U_{i d q 0}-E_{d q 0}=R_{3} I_{d q 0}+L_{3} \frac{d I_{d q 0}}{d t}+L_{3}\left[\begin{array}{c}
-\omega I_{q} \\
\omega I_{d} \\
0
\end{array}\right]
$$

where $U_{i d q 0}=P U_{i a b c}, E_{d q 0}=P E_{a b c}, I_{d q 0}=P I_{a b c}$, and $P$ is the Park transformation matrix given in (11). Consider

$$
P=\frac{2}{3}\left[\begin{array}{ccc}
\sin (\omega t) & \sin \left(\omega t-\frac{2 \pi}{3}\right) & \sin \left(\omega t+\frac{2 \pi}{3}\right) \\
\cos (\omega t) & \cos \left(\omega t-\frac{2 \pi}{3}\right) & \cos \left(\omega t+\frac{2 \pi}{3}\right) \\
\frac{1}{2} & \frac{1}{2} & \frac{1}{2}
\end{array}\right]
$$

Equation (10) may be written in (12) and (13). Consider

$$
\begin{aligned}
& L_{3} \frac{d I_{d}}{d t}=-R_{3} I_{d}+\omega L_{3} I_{q}-E_{d}+U_{i d}=U_{3 d}+U_{i d}, \\
& L_{3} \frac{d I_{q}}{d t}=-R_{3} I_{q}-\omega L_{3} I_{d}-E_{q}+U_{i q}=U_{3 q}+U_{i q},
\end{aligned}
$$

where

$$
\begin{aligned}
& U_{3 d}=-R_{3} I_{d}+\omega L_{3} I_{q}-E_{d}, \\
& U_{3 q}=-R_{3} I_{q}-\omega L_{3} I_{d}-E_{q} .
\end{aligned}
$$

$U_{i d}$ and $U_{i q}$ in (12) and (13) are control variables that control the DC-AC VSC converter.

The MPPT algorithm computes the duty cycle to control the DC boost converter. The relationship of inputs and outputs of the DC boost converter is depicted by (16) and (17). Consider

$$
\begin{aligned}
i_{\mathrm{dcl}} & =(1-D) i_{s}, \\
u_{s} & =(1-D) u_{\mathrm{dc}},
\end{aligned}
$$

where $D$ is the duty cycle of the DC boost converter. 
The instantaneous active and reactive powers are defined by (18) and (19). Consider

$$
\begin{aligned}
& p=E_{d} I_{d}+E_{q} I_{q}, \\
& q=-E_{d} I_{q}+E_{q} I_{d} .
\end{aligned}
$$

Selecting $E_{q}=0$, (18) and (19) change into the two following equations:

$$
\begin{aligned}
& p=E_{d} I_{d}, \\
& q=-E_{d} I_{q} .
\end{aligned}
$$

The model above can be used to design the synergetic control of the grid-connected PV system.

\section{Synergetic Control of a Grid-Connected PV System in Normal Operation}

Control strategies of the DC boost converter and the DC-AC VSC converter in the grid-connected PV system must be made. MPPT is implemented in the DC boost converter in normal operation. There are a number of MPPT algorithms; however, this paper does not analyze them.

The DC-AC VSC converter is controlled using the synergetic control presented in this paper. The control variables $U_{i d}$ and $U_{i q}$ in (12) and (13) are derived by synergetic control theory.

The reference value of $I_{d}$ may be obtained from the external voltage control loop.

$$
I_{d \_ \text {ref }}=\left(K_{P}+\frac{K_{i}}{s}\right)\left(u_{\mathrm{dc}}-u_{\mathrm{dc} \_ \text {ref }}\right)=K_{P}\left(u_{\mathrm{dc}}-u_{\mathrm{dc} \_ \text {ref }}\right)+I_{u} \text {, }
$$

where $I_{u}=K_{i} / s\left(u_{\mathrm{dc}}-u_{\mathrm{dc} \_ \text {ref }}\right)$; that is,

$$
\frac{d I_{u}}{d t}=K_{i}\left(u_{\mathrm{dc}}-u_{\mathrm{dc} \_ \text {ref }}\right),
$$

where $K_{P}$ is the gain of the proportional term, $K_{i}$ is the gain of the integral term, $u_{\text {dc_ref }}$ is the reference value of the DC voltage $u_{\mathrm{dc}}$, and subscript ref denotes a reference value.

There are 2 control variables, and therefore, 2 macrovariables must be selected. The first macrovariable is

$$
\psi_{1}=I_{d \_ \text {ref }}-I_{d}=K_{P}\left(u_{\mathrm{dc}}-u_{\text {dc_ref }}\right)+I_{u}-I_{d} .
$$

Substituting (24) into (4), (25) is obtained:

$$
T_{1}\left(K_{P} \frac{d u_{\mathrm{dc}}}{d t}+\frac{d I_{u}}{d t}-\frac{d I_{d}}{d t}\right)+\psi_{1}=0 .
$$

Substituting (12), (23), and (24) into (25), the first control variable is computed by (26) as follows:

$$
\begin{aligned}
U_{i d}= & K_{P} L_{3} \frac{d u_{\mathrm{dc}}}{d t}+K_{i} L_{3}\left(u_{\mathrm{dc}}-u_{\mathrm{dc} \_ \text {ref }}\right) \\
& +\frac{L_{3}}{T_{1}}\left(I_{d \_ \text {ref }}-I_{d}\right)-U_{3 d} .
\end{aligned}
$$

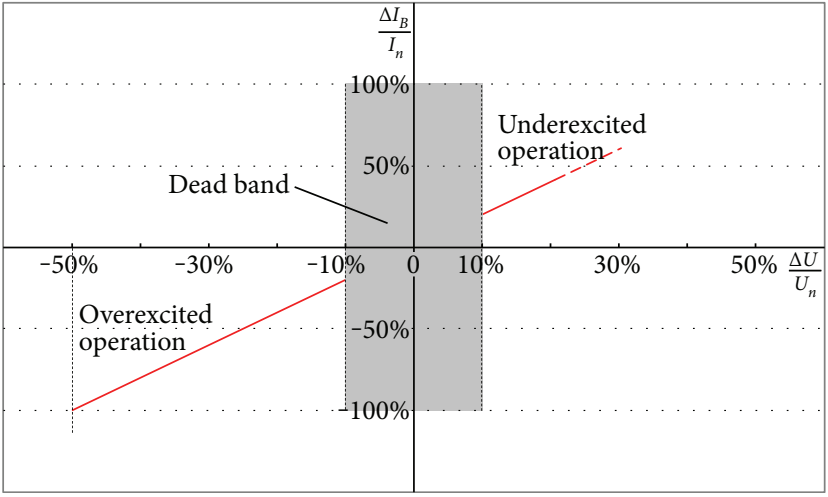

FIGURE 4: Principle of voltage support in the event of grid faults.

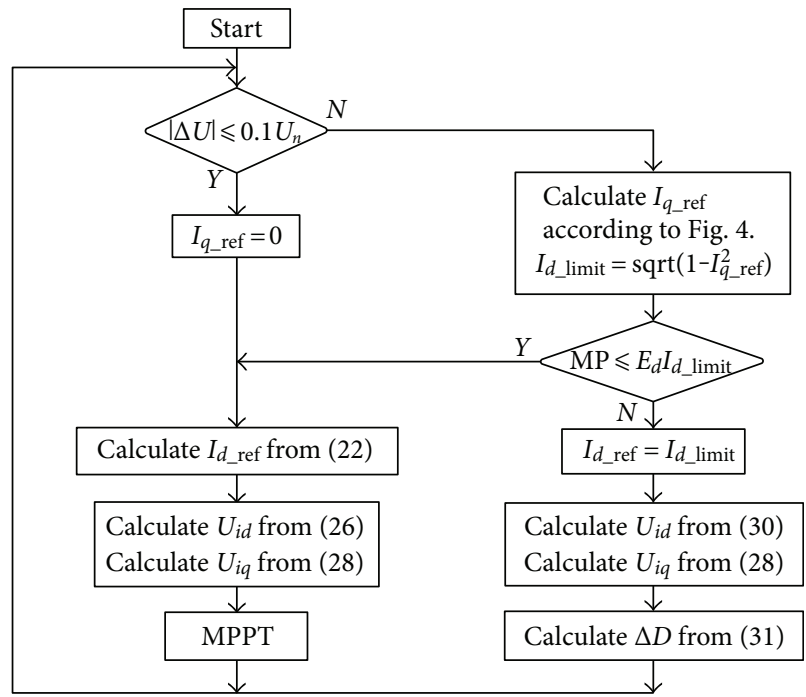

Figure 5: Synergetic control strategies of the PV system.

The second macrovariable is selected

$$
\psi_{2}=I_{q-\mathrm{ref}}-I_{q},
$$

where $I_{q_{\text {_ref }}}$ is a constant.

Substituting (27) into (4) and considering (13), the second control variable is as follows:

$$
U_{i q}=\frac{L_{3}}{T_{2}}\left(I_{q \_ \text {ref }}-I_{q}\right)-U_{3 q} .
$$

The control variables $U_{i d}$ and $U_{i q}$ are computed by (26) and (28), respectively, to guarantee system stability in normal operation. The synergetic control scheme of the grid-connected PV system is shown in Figure 3.

\section{Synergetic Control during LVRT}

The PV system should stay connected and support the grid with reactive power during the voltage dip. Therefore, the reference value of $I_{q}$ is $I_{q_{\text {_ref }}}=$ const., depending on the voltage magnitude. Figure 4 depicts the principle of voltage support in the event of grid faults [17].

The abscissa in Figure 4 stands for $\Delta U / U_{n}$, and the ordinate is $\Delta I_{B} / I_{n} . \Delta U=U-U_{0}$ and $\Delta I_{B}=I_{B}-I_{B 0}$, where $U$ 


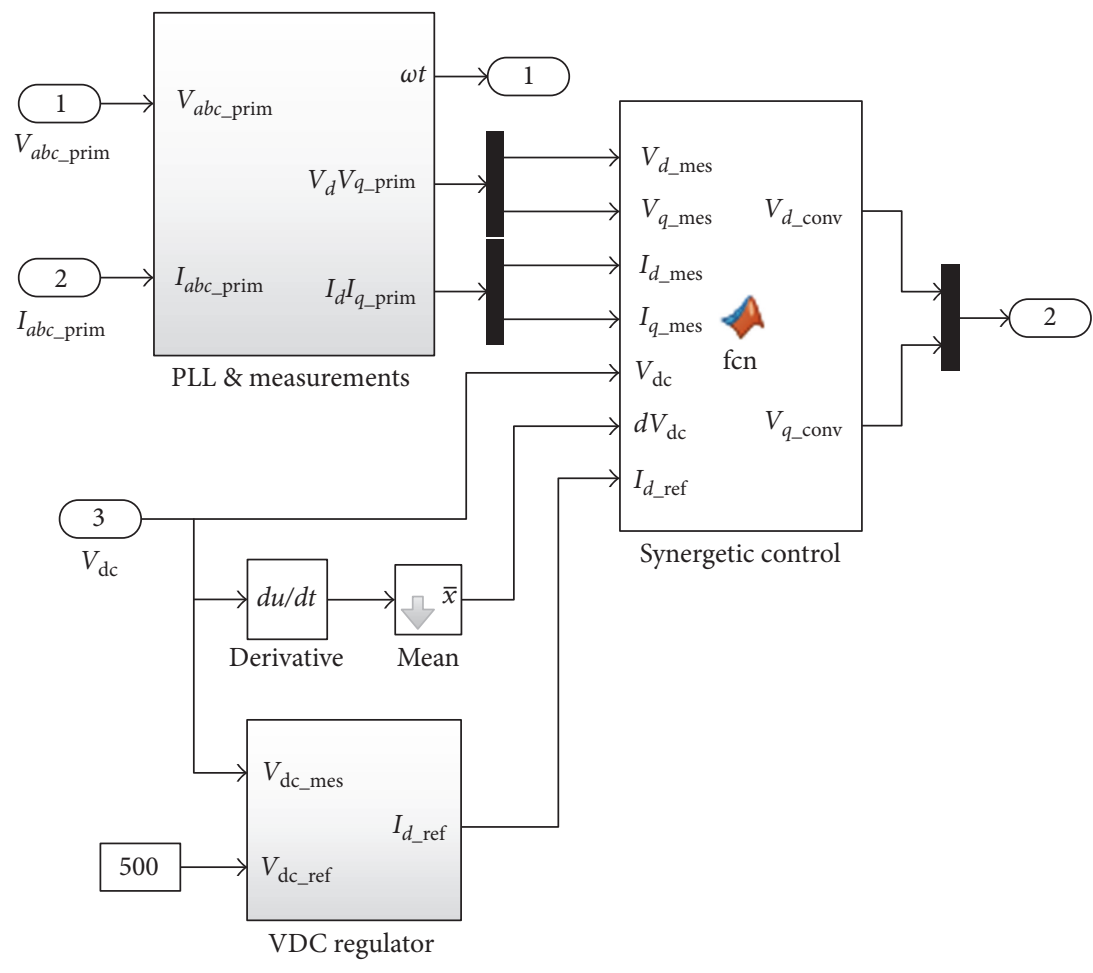

FIGURE 6: VSC main controller.

is the present voltage during the fault, $U_{n}$ is the rated voltage, $U_{0}$ is voltage before the fault, $I_{B}$ is the reactive current, $I_{n}$ is the rated current, and $I_{B 0}$ is the reactive current before the fault. If a voltage dip is more than $10 \%$ of the rated voltage, the generator should provide a reactive current amounting to at least $2 \%$ of the rated current for each percent of the voltage dip within $20 \mathrm{~ms}$ after fault recognition [17]. If a voltage dip is more than $50 \%$ of the rated voltage, the generator must inject the grid with a reactive power of $100 \%$ of the rated current.

The limitation of $I_{d}$ is $I_{d \_ \text {limit }}=\sqrt{1-I_{q_{-} \text {ref }}^{2}} \mathrm{pu}$, so the current will not be greater than the rated current.

If the maximum power of the PV array at MPP is less than the power $E_{d} I_{d \_l i m i t}$, the maximum power can be injected into the grid with $I_{d}<I_{d \text { _limit. }}$. A MPPT is used during LVRT to obtain the maximum power and economic benefits, and the control strategies are the same as those in normal operation.

If the maximum power of the PV array at MPP is more than the power $E_{d} I_{d \_ \text {limit }}, I_{d_{\text {_ref }}}=I_{d_{\text {_limit }}}$ is set, and the power output of the PV array equals $E_{d} I_{d \_ \text {limit }}$ for the power balance. The following control strategies are used:

The first macrovariable is selected as

$$
\psi_{1}=I_{d_{-} \text {ref }}-I_{d} .
$$

Substituting (29) into (4) and considering (12), the first control variable is computed as follows:

$$
U_{i d}=\frac{L_{3}}{T_{1}}\left(I_{d \_ \text {ref }}-I_{d}\right)-U_{3 d} .
$$

Equation (28) is also used for the second control variable during LVRT.

A MPPT is not used, and the duty cycle $D$ is determined by a PI controller to regulate the DC link voltage.

$$
\begin{aligned}
\Delta D & =\left(K_{P D}+\frac{K_{i D}}{s}\right)\left(u_{\mathrm{dc} \_ \text {ref }}-u_{\mathrm{dc}}\right), \\
D & =D_{0}+\Delta D
\end{aligned}
$$

where $D_{0}$ is the initial value of $D$.

The duty cycle of the DC boost converter is determined by (31) and (32) during LVRT. The DC-AC VSC converter is controlled on the basis of (28) and (30).

The control strategies described above are shown in Figure 5.

Equations (26) and (30) are derived according to the synergetic control algorithm. $I_{d_{-} \text {ref }}$ is variable and is computed by (22) in normal operation. Consequently, (26) is obtained for the control of the PV system in normal operation. $I_{d \_ \text {ref }}$ is a constant, and (30) is derived for the second control strategy during LVRT. Equations (26) and (30) are used under different operating conditions of the gridconnected PV system.

The DC link voltage $u_{\mathrm{dc}}$ should remain stable to maintain good operation of the PV system. This requires a power balance in the PV system. If the power injected into the grid by the DC-AC converter is less than the output power of the $\mathrm{PV}$ array, $u_{\mathrm{dc}}$ will increase. If the output power of the converter is the same as the output power of the PV array, $u_{\mathrm{dc}}$ will not change. The two control strategies can satisfy 
the power balance in the PV system in normal operation and during a LVRT.

The PV array works at the MPP because of the MPPT in normal operation. If the output power of the converter is less than the output power of the PV array and $u_{\mathrm{dc}}$ increases, the DC voltage regulator will generate greater $I_{d_{-} \text {ref }}$ on the basis of (22). The synergetic control will result in more output power of the converter and achieve a power balance in the $\mathrm{PV}$ system after the regulation process.

The synergetic control maintains the output power $E_{d} I_{d \text { _limit }}$ of the converter for the second control strategy during LVRT. If the output power of the PV array is greater than $E_{d} I_{d_{\text {_limit }}}$ and $u_{\mathrm{dc}}$ increases, the DC voltage regulator will give a smaller $D$ according to (31) and (32). The voltage of the PV array will increase according to (17), and its output power will decrease due to the power-voltage characteristics of the PV array. The power balance in the PV system will be achieved once more, and $u_{\mathrm{dc}}$ will return to its reference value.

The DC-AC converter may be damaged due to the large current that passes through it. The two control strategies can prevent the converter from overcurrent in normal operation and during LVRT.

\section{Case Studies}

Matlab software provides an example titled Detailed Model of a 100-kW Grid-Connected PV Array [9]. The controllers of the example are adapted to assess the performance of synergetic control of the grid-connected PV system.

The example includes a PV array with an open-circuit voltage of $321 \mathrm{~V} . u_{\mathrm{dc} \_ \text {ref }}$ is $500 \mathrm{~V}$, and the rated AC voltage is $260 \mathrm{~V}$. A distribution transformer has a voltage ratio of $25 \mathrm{kV} / 260 \mathrm{~V}$.

6.1. Normal Operation Simulation. MPPT used in the case study is based on incremental conductance with an integral controller that can ensure that the system operates in MPP when the radiation intensity and temperature change rapidly.

The DC-AC converter is controlled using a synergetic control scheme. Equations (26) and (28) are rewritten according to the symbols in the Matlab example [9]:

$$
\begin{aligned}
& V_{d_{-} \text {conv }}=K_{P} L_{3} \frac{d V_{\mathrm{dc}}}{d t}+K_{i} L_{3}\left(V_{\mathrm{dc}}-V_{\mathrm{dc} \_ \text {ref }}\right) \\
& +\frac{L_{3}}{T_{1}}\left(I_{d \_ \text {ref }}-I_{d}\right)+R_{3} I_{d \_ \text {ref }}-\omega L_{3} I_{q \_ \text {ref }}+V_{d \_ \text {mes }}, \\
& V_{q_{-} \text {conv }}=\frac{L_{3}}{T_{2}}\left(I_{q_{-} \text {ref }}-I_{q}\right)+R_{3} I_{q_{-} \text {ref }}+\omega L_{3} I_{d_{-} \text {ref }}+V_{q_{-} \text {mes }} .
\end{aligned}
$$

Figure 6 shows the VSC main controller containing synergetic control.

The VDC regulator in Figure 6 is constructed on the basis of (22). The inputs of the PLL and measurements block are primary voltages $V_{a b c_{\text {_p }} \text { rim }}$ and currents $I_{a b c_{\text {_p }} \text { rim }}$ of the distribution transformer. This block tracks the frequency

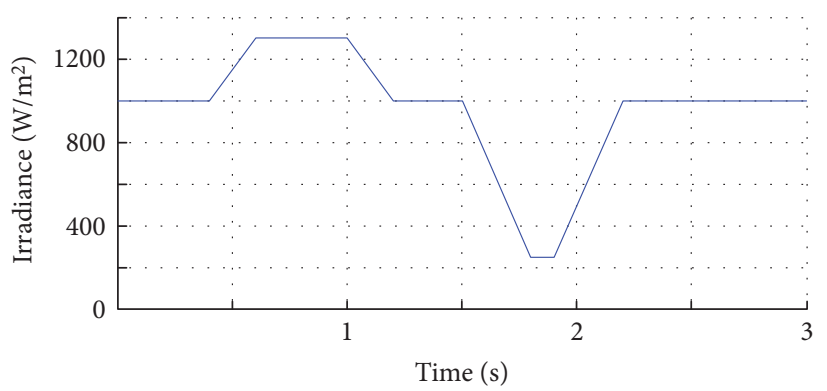

FIGURE 7: Sun irradiance.

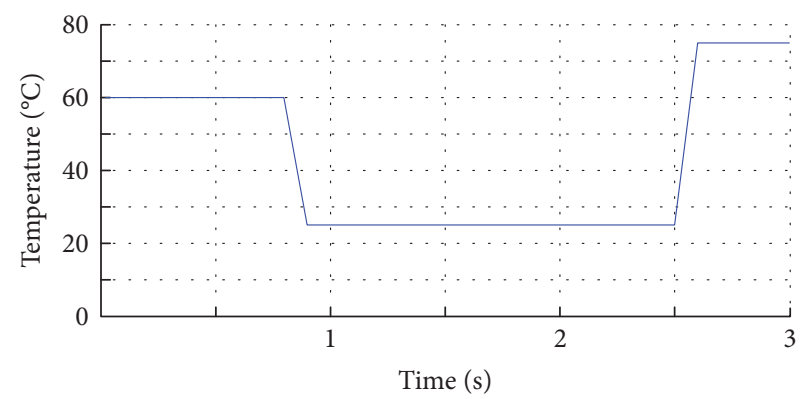

FIGURE 8: Temperature.

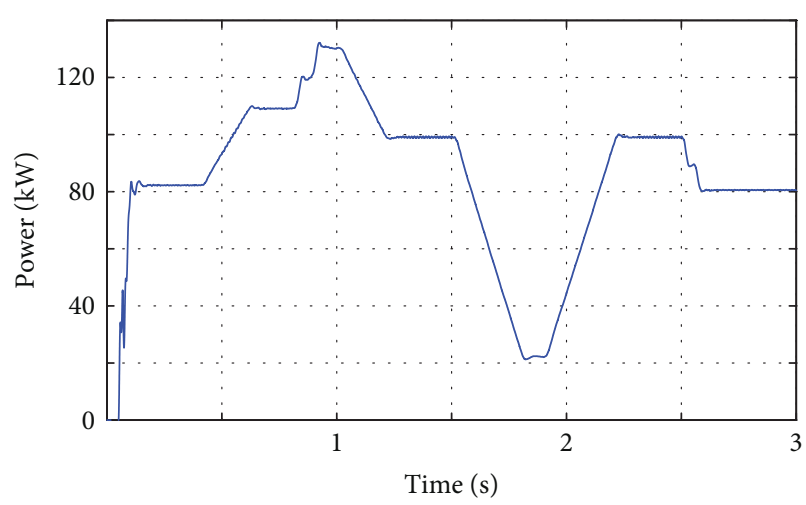

Figure 9: PV array output power.

and phase of a sinusoidal three-phase signal and performs Park transformation from a three-phase $(a b c)$ reference frame to a $d q 0$ reference frame. The synergetic control block in Figure 6 is a Matlab function block. It includes Matlab code. The code computes 2 control variables, $V_{d_{\text {c conv }}}$ and $V_{\text {q_conv }}$, with (33) and (34). The control variables are transformed into the reference values of three-phase voltages to generate PWM and control the VSC converters.

The parameters $K_{P}=0.2, K_{i}=150, T_{1}=0.01$, and $T_{2}=0.01$ are selected and applied in (22), (33), and (34). The settings are $V_{d_{\text {_ref }}}=500 \mathrm{~V}$ and $I_{q_{\text {_ref }}}=0$ for the simulation in normal operation. The standard test conditions are $1000 \mathrm{~W} / \mathrm{m}^{2}$ irradiance and $25^{\circ} \mathrm{C}$ temperature. The change of sun irradiance is shown in Figure 7. Figure 8 describes the change of temperature for the simulation.

The MPPT regulator changes the duty cycle to regulate the PV voltage for tracking maximum power. At $t=0.1 \mathrm{sec}$, 


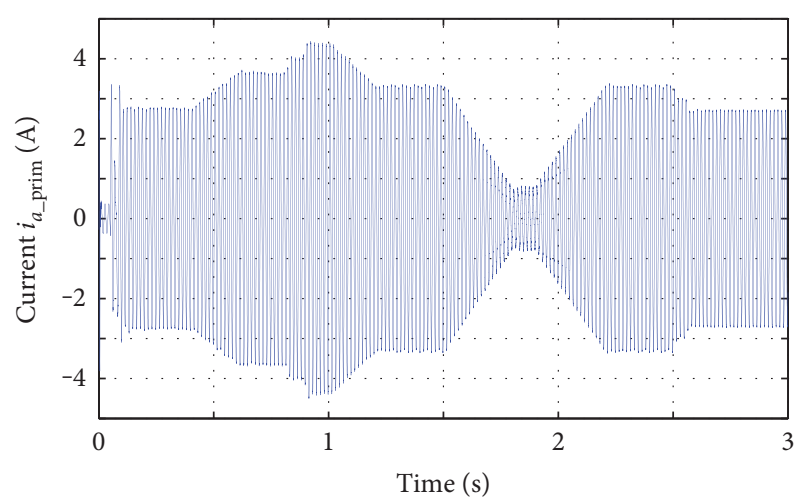

FIGURE 10: Primary current $i_{a_{-} \text {prim }}$.

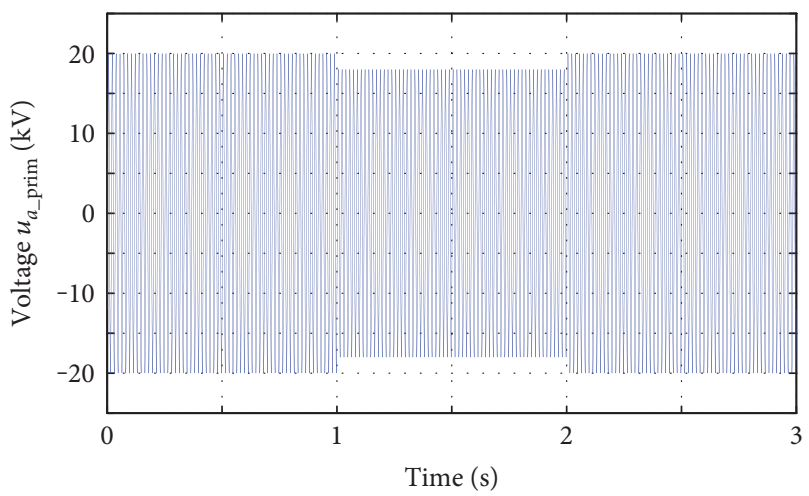

FIgURe 11: Bus voltage decrease.

the MPPT is enabled, and Figure 9 shows the PV array output power. Maximum power is $100.4 \mathrm{~kW}$ at the standard test conditions. VSC converters deliver the power to the grid by synergetic control.

The root mean square (RMS) of the primary voltage $v_{a_{\text {_pprim }}}$ of the distribution transformer is constant. The RMS of the current $i_{a_{-} \text {prim }}$ is directly proportional to the power. Figure 10 shows the primary current $i_{a_{-} \text {prim }}$ of the distribution transformer.

Figures 9 and 10 indicate that the grid-connected PV system can track maximum power and deliver the power to the grid when the radiation and temperature change rapidly. The system operates stably.

The bus voltage may change in normal operation. Simulation of voltage fluctuation is performed at the standard test conditions. Figure 11 depicts a $25 \mathrm{kV}$ bus voltage $v_{a_{-} \text {prim }}$. The RMS of $v_{a-\text { prim }}$ decreases by $10 \%$ at $t=1 \mathrm{sec}$.

The current $i_{a_{\text {pprim }}}$ is shown in Figure 12. $i_{a_{-} \text {prim }}$ increases when the bus voltage decreases.

The maximum power does not change because sun irradiance and temperature are constant at the standard test conditions. Figure 13 demonstrates that the power injected into the grid is almost constant during the grid voltage fluctuation. This means that the synergetic control performs well in normal operation.

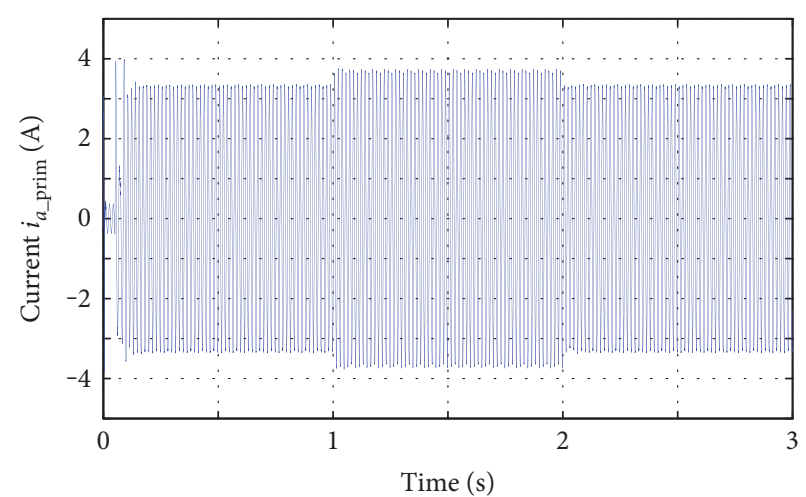

FIgURE 12: Current increase.

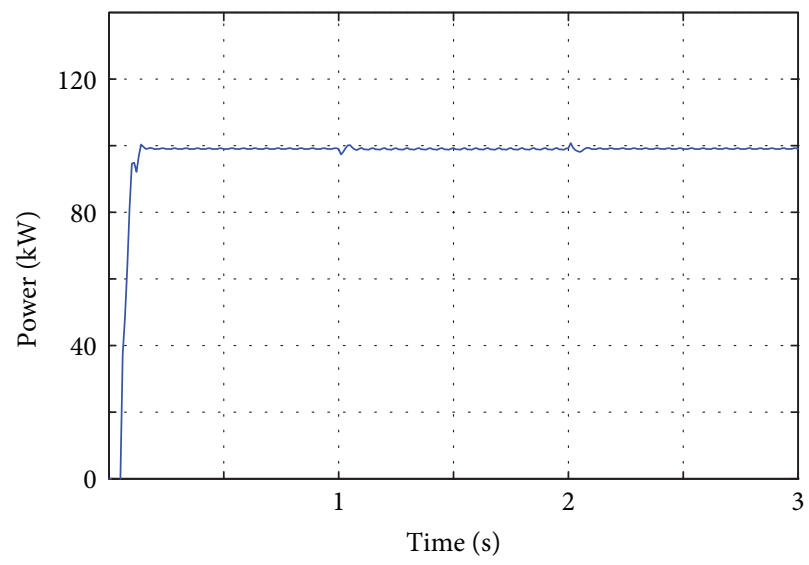

Figure 13: Power invariance.

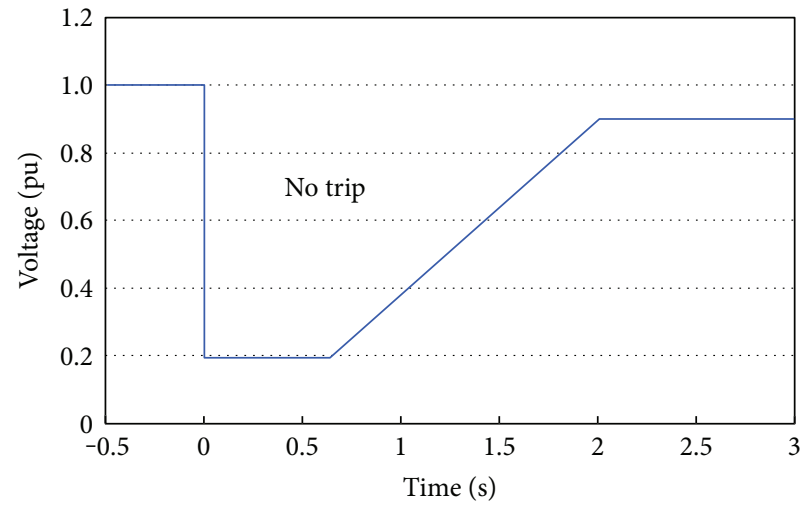

Figure 14: LVRT requirement.

6.2. LVRT Simulation. LVRT is the capability of electric generators to stay connected to the grid during short periods of voltage dip. LVRT is an important feature of the generator control system. There are several standards for LVRT requirements $[17,18]$. Figure 14 shows the LVRT requirement in [19]. These requirements may be used for large solar power installations. 


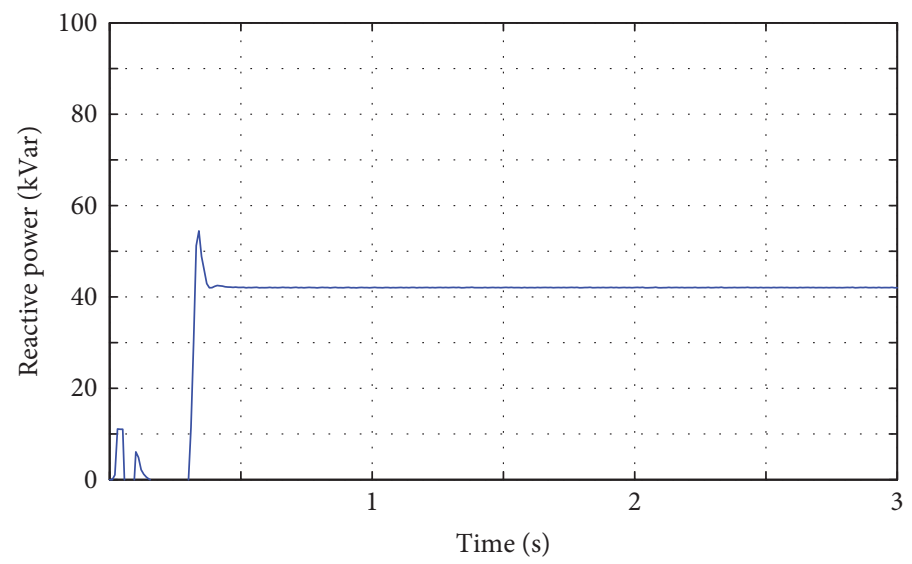

FIGURE 15: Reactive power injected into the grid at a $30 \%$ decrease of the bus voltage.

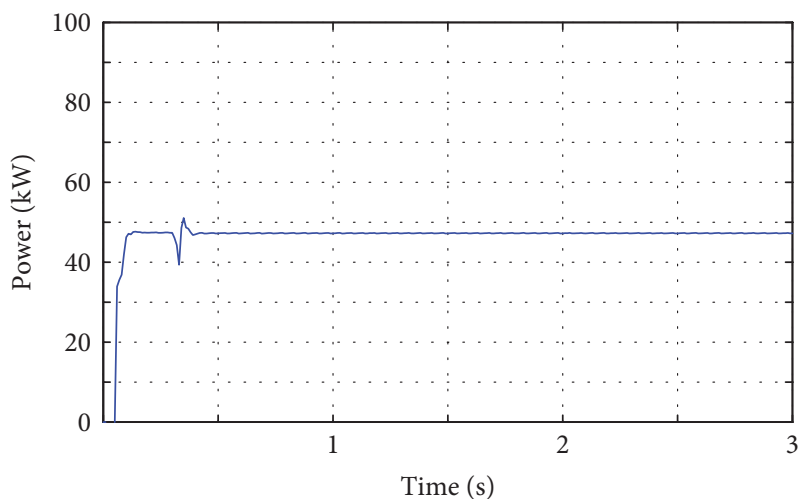

Figure 16: Active power injected into the grid at a $30 \%$ decrease of grid voltage.

Three cases are used to test the performances of the synergetic control during a LVRT. The three-phase fault block in Simulink is connected in utility grid to simulate a three-phase short circuit with arc resistances.

The feature of the PV system is tested first when the bus voltage decreases by $30 \%$ due to a grid fault. The reference value of the reactive current $I_{q}$ is $I_{q_{-} \text {ref }}=-0.6 \mathrm{pu}$ on the basis of Figure 4 . The limitation of $I_{d}$ is $I_{d \_ \text {limit }}=0.8$, and the power is $E_{d} I_{d \text { _limit }}=0.56 \mathrm{pu}$. The maximum power of the PV array at MPP is $0.48 \mathrm{pu}$ when it is simulated at an irradiance of $500 \mathrm{~W} / \mathrm{m}^{2}$ and a temperature of $25^{\circ} \mathrm{C}$. The first control strategy is used because the maximum power of the $\mathrm{PV}$ array at MPP is less than $E_{d} I_{d_{\text {_limit }}} . I_{q_{-} \text {ref }}=-0.6$ is set; the other settings are equivalent to those used in the normal operation simulation. Equations (22), (33), and (34) and MPPT are used. The RMS of the voltage $v_{a_{\text {_prim }}}$ decreases by $30 \%$ at $t=0.3 \mathrm{~s}$, and the simulation results are shown in Figures 15-17.

Figure 15 depicts the reactive power injected into the grid. The PV system provides the grid with a reactive power of $42 \mathrm{kVar}$ during the LVRT.

The active power injected into the grid is shown in Figure 16. The injected active power is $47.2 \mathrm{~kW}$ when the reactive power injected into the grid is $42 \mathrm{kVar}$ at a $30 \%$ decrease of the grid voltage. The maximum power of the

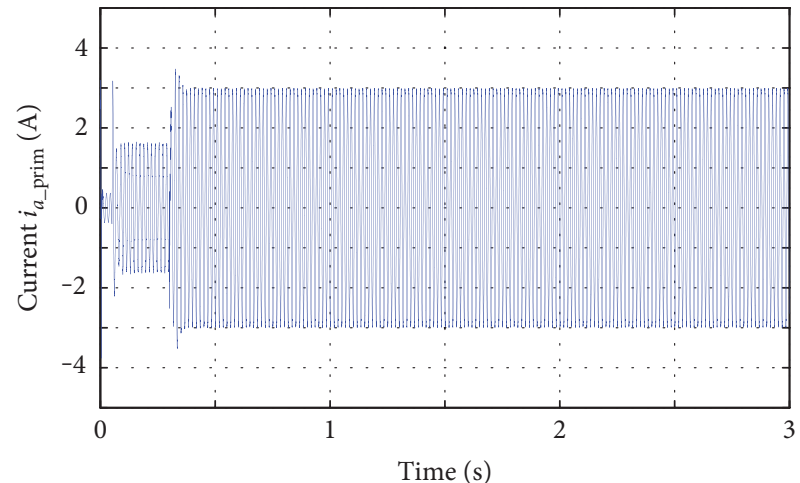

Figure 17: Primary current at a $30 \%$ decrease of grid voltage.

PV array at MPP is delivered to the grid, and the solar energy is fully utilized.

The rated primary current is $3.3 \mathrm{~A}$. Figure 17 shows that the primary current is less than its rated value. Therefore, the PV system may stay connected to the grid and provide the grid with $47.2 \mathrm{~kW}$ and $42 \mathrm{kVar}$ at a $30 \%$ decrease of the grid voltage due to grid fault.

Then, simulations will test the performances of the synergetic control when the grid voltage decreases to 0.2 pu. The second control strategy is used because $I_{q \_ \text {ref }}=-1$ according to Figure 4 and $I_{d \_l i m i t}=0$. The duty cycle $D$ is computed according to (31) and (32). Equation (30) is rewritten using the symbols in [9]:

$$
V_{d_{-\mathrm{conv}}}=\frac{L_{3}}{T_{1}}\left(I_{d_{\text {ref }}}-I_{d}\right)+R_{3} I_{d_{\_} \mathrm{ref}}-\omega L_{3} I_{q \_ \text {ref }}+V_{d_{-\mathrm{mes}}} .
$$

Equations (31), (32), (34), and (35) are used to compute the control variables for controlling the $\mathrm{DC}$ boost converter and the VSC converters during LVRT. The parameters are $K_{P D}=0.01, K_{i D}=0.1, T_{1}=0.01$, and $T_{2}=0.01$. The settings are $V_{d_{\text {_ref }}}=500 \mathrm{~V}, I_{q_{\text {_ref }}}=-1$, and $I_{d_{\text {_ref }}}=0 \mathrm{pu}$.

A three-phase short circuit occurs in the power distribution system at $t=0.3 \mathrm{sec}$ for the LVRT simulation. The bus voltage decreases to $0.2 \mathrm{pu}$ during short circuit. $v_{a_{-} \text {prim }}$ and 


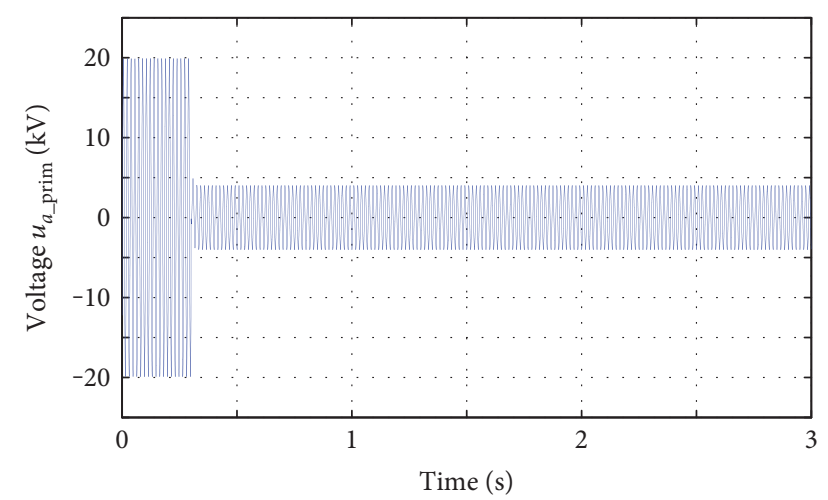

Figure 18: $25 \mathrm{kV}$ bus voltage during LVRT.

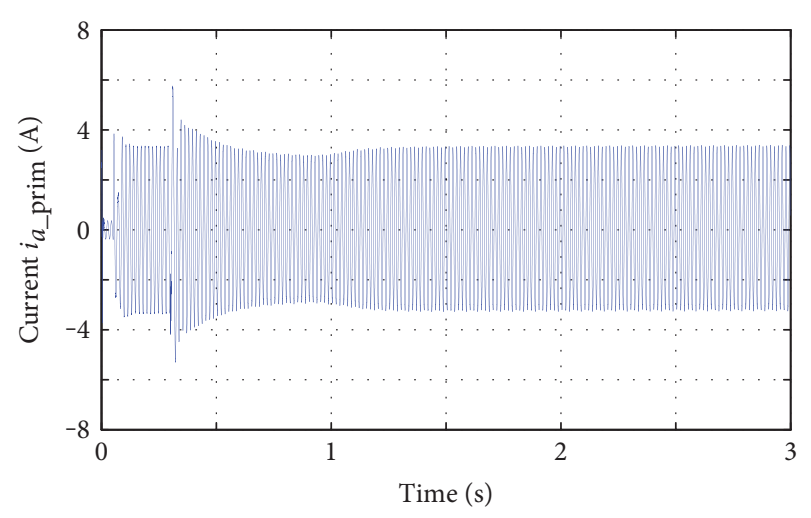

FIGURE 19: Primary current during LVRT.

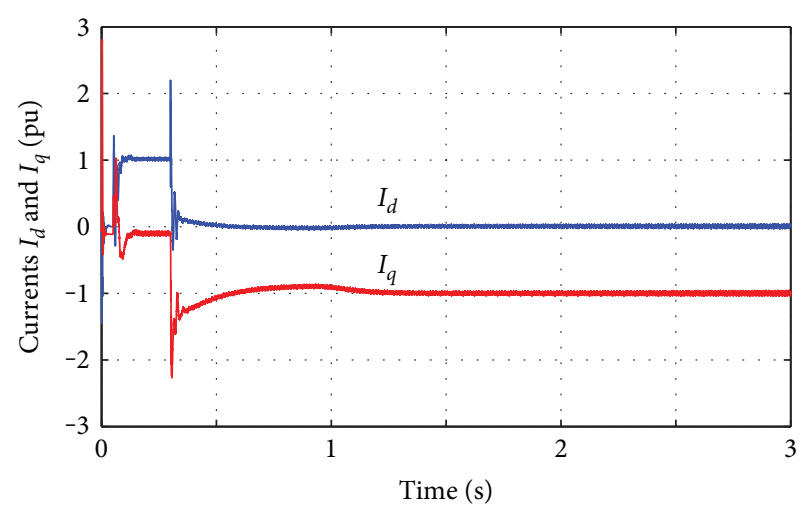

Figure 20: Currents $I_{d}$ and $I_{q}$ during LVRT.

$i_{a_{-} \text {prim }}$ are shown in Figures 18 and 19, respectively. The $25 \mathrm{kV}$ bus voltage in Figure 18 decreases to $0.2 \mathrm{pu}$ after $t=0.3 \mathrm{sec}$.

Small fluctuations of primary current arise after the voltage dip. The peak value of $i_{a_{-} \text {prim }}$ during LVRT is less than double of that in normal operation.

Currents $I_{d}$ and $I_{q}$ are depicted in Figure 20. $I_{d}$ and $I_{q}$ are regulated to 0 and $-1 \mathrm{pu}$, respectively, after the dip. The PV system stays connected and supports the grid with reactive power.

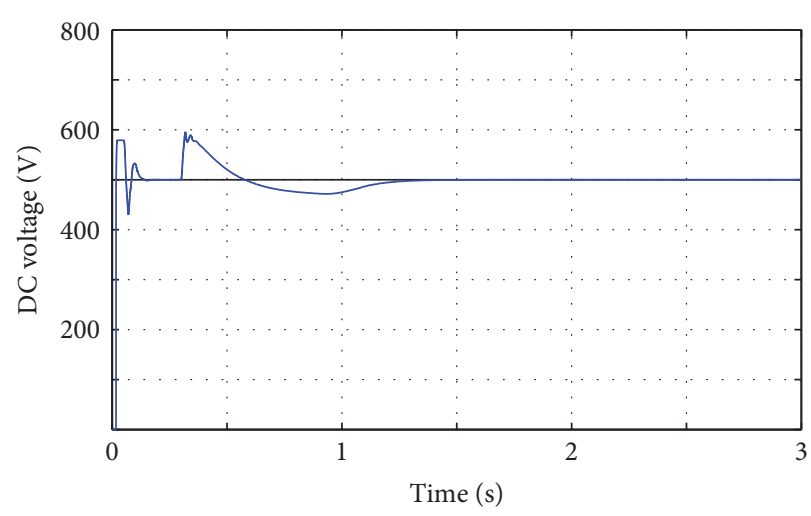

FIgURe 21: DC link voltage $V_{\mathrm{dc}}$.

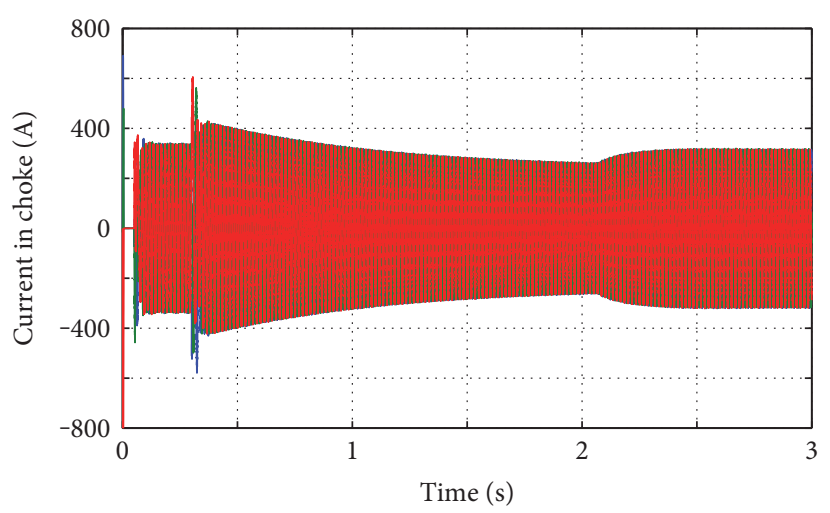

FIgURE 22: Three-phase currents flowing in the choke.

The DC link voltage $V_{\mathrm{dc}}$ is shown in Figure 21. It fluctuates slightly and then remains at $500 \mathrm{~V}$ after the dip.

Another simulation is made for testing the performance of the synergetic control at a bus voltage of $0.05 \mathrm{pu}$. The second control strategy is used. A three-phase short circuit is applied in the bus at $t=0.3 \mathrm{sec}$, and the bus voltage decreases to $0.05 \mathrm{pu}$ to simulate the voltage of the fault arc. The current settings are $I_{d_{-} \text {ref }}=0$ and $I_{q_{\text {_ref }}}=-0.9 \mathrm{pu}$, to avoid a large current. The reference value of current $I_{q}$ is $I_{q \_ \text {ref }}=-1 \mathrm{pu}$, to provide the grid with reactive power after $t=0.35 \mathrm{sec}$. Figure 22 shows three-phase currents flowing in the choke. The maximum value of the current is less than $2.0 \mathrm{pu}$. Synergetic control can limit the current peak during LVRT.

The example in [9] has the current regulator with PI control and simulates only the normal operation of the PV system. The regulator from (31) and (32) is added to the example to simulate the LVRT of the PV system. $I_{d \_ \text {ref }}=0$ and $I_{q \_ \text {ref }}=-1 \mathrm{pu}$ are fixed. Two parameters of the current regulator with PI control are changed from 0.3 and 20 (for normal operation) to 0.03 and 0.002 , respectively, for LVRT. Therefore, parameter tuning of the current regulator with PI control is difficult. Chatter has been the main obstacle for sliding-mode control systems [10]. Probabilistic wavelet fuzzy neural networks (PWFNNs) include a membership layer, probabilistic layer, wavelet layer, and rule layer [11]. PWFNNs are very complicated, such that it is difficult to 
determine the PWFNN parameters. The gains of the PI controller in [13] must be changed online using the CMPN algorithm for improving the LVRT capability of gridconnected PV systems.

The parameters of the synergetic controller described in this paper are invariant during normal operations and during LVRT, and parameter $T_{1}$ equals $T_{2}$. There is no need to change the parameters of the synergetic controller with a complicated algorithm. Therefore, parameter tuning of the synergetic controller is easy, and the controller is sufficiently robust for use in the PV system. The design of the synergetic controller is simple and does not require linearization of the PV system. In addition, the proposed control schemes are easy to realize. The synergetic control is chatter-free and displays good static and dynamic performance.

Asymmetric short circuit faults may occur in power systems. Unbalanced grid voltages are comprised of positive, negative, and zero sequence voltage components. The zero sequence is not considered here because of three-wire systems. Unbalanced grid voltage sags will cause performance deterioration of the converter. Negative sequences result in DC-link voltage ripples and harmonic power. The positive and negative sequence currents should be controlled simultaneously to improve control performance. Reference [20] used separate current controllers for positive and negative sequences. Synergetic control may be used in two current controllers to control positive and negative sequence currents separately. It is possible to use synergetic control for improving the performance of $\mathrm{PV}$ systems during unbalanced voltage sags.

\section{Conclusions}

Solar PV is an important renewable energy technology and does not generate pollution. PV systems are developing rapidly, and most PV systems are grid-connected. Research on the control of grid-connected PV systems contributes to the improvement of the operation of the distribution network and the PV system.

Synergetic control can be used for the control of a gridconnected PV system. The design of a synergetic controller does not require the linearization of the PV system. The mathematical expressions for computing control variables can be derived according to the synergetic control algorithm and the mathematical model of a grid-connected PV system. Two control strategies are used in normal operation and during LVRT. The parameters $T_{1}$ and $T_{2}$ of the two synergetic controllers are the same. The parameters of the synergetic controllers are easy to determine, and results indicate that the synergetic controllers are robust. The gridconnected PV system can obtain a maximum power point and inject the power into the grid when the radiation and temperature change rapidly. The DC link voltage and AC currents are limited, and the DC-AC VSC converters are not damaged during LVRT. The PV system can run with $I_{q}=-1$ pu continuously and supply reactive power to the grid when the grid voltage decreases to $0.05 \mathrm{pu}$.

Synergetic control has good dynamic characteristics in normal operation and during LVRT and is the alternative solution for grid-connected PV systems.

\section{Conflicts of Interest}

The authors declare that there is no conflict of interests regarding the publication of this paper.

\section{Acknowledgments}

This work was financially supported by the National Natural Science Foundation of China $(51177074,51407095)$ and the Jiangsu Province Natural Science Foundation (BK20151548).

\section{References}

[1] A. Rosa, Fundamentals of Renewable Energy Processes, Academic Press, Boston, MA, USA, 2012.

[2] REN21, Renewables 2016 Global Status Report, REN21 Secretariat, Paris, France, 2016, http://www.ren21.net/wpcontent/uploads/2016/06/GSR_2016_Full_Report_REN21.pdf.

[3] N. Femia, G. Petrone, G. Spagnuolo, and M. Vitelli, "Optimization of perturb and observe maximum power point tracking method," IEEE Transactions on Power Electronics, vol. 20, no. 4, pp. 963-973, 2005.

[4] K. H. Hussein, I. Muta, T. Hoshino, and M. Osakada, "Maximum photovoltaic power tracking: an algorithm for rapidly changing atmospheric conditions," IEE ProceedingsGeneration, Transmission and Distribution, vol. 142, no. 1, pp. 59-64, 1995.

[5] P. Q. Dzung, L. D. Khoa, H. H. Lee, L. M. Phuong, and N. T. D. Vu, "The new MPPT algorithm using ANN based PV," in Proceedings of the International Forum on Strategic Technology, pp. 402-407, Ulsan, South Korea, 13-15 October 2010.

[6] N. Zakzouk, M. Elsaharty, A. Abdelsalam, A. Helal, and B. Williams, "Improved performance low-cost incremental conductance PV MPPT technique," IET Renewable Power Generation, vol. 10, no. 4, pp. 561-574, 2016.

[7] K. Sundareswaran, V. Vigneshkumar, P. Sankar, S. Simon, P. Nayak, and S. Palani, "Development of an improved $\mathrm{P} \& \mathrm{O}$ algorithm assisted through a colony of foraging ants for MPPT in PV system," IEEE Transactions on Industrial Informatics, vol. 12, no. 1, pp. 187-200, 2016.

[8] S. Mohanty, B. Subudhi, and P. Ray, "A new MPPT design using grey wolf optimization technique for photovoltaic system under partial shading conditions," IEEE Transactions on Sustainable Energy, vol. 7, no. 1, pp. 181-188, 2016.

[9] MathWorks, Detailed Model of a 100-kW Grid-Connected PV Array, MathWorks, Natick, MA 01760-2098, USA, 2015, http://www.mathworks.com/examples/simpower/mw/sps_ product-power_PVarray_grid_det-detailed-model-of-a-100-kwgrid-connected-pv-array.

[10] N. Kumar, T. Saha, and J. Dey, "Sliding-mode control of PWM dual inverter-based grid-connected PV system: modeling and performance analysis," IEEE Journal of Emerging Selected Topics in Power Electronics, vol. 4, no. 2, pp. 435-444, 2016.

[11] F. Lin, K. Lu, and T. Ke, "Probabilistic wavelet fuzzy neural network based reactive power control for grid-connected three-phase PV system during grid faults," Renewable Energy, vol. 92, pp. 437-449, 2016.

[12] J. Sosa, M. Castilla, J. Miret, J. Matas, and Y. Al-Turki, "Control strategy to maximize the power capability of PV three-phase inverters during voltage sags," IEEE Transactions on Power Electronics, vol. 31, no. 4, pp. 3314-3323, 2016. 
[13] H. M. Hasanien, “An adaptive control strategy for low voltage ride through capability enhancement of grid-connected photovoltaic power plants," IEEE Transactions on Power Apparatus and Systems, vol. 31, no. 4, pp. 3230-3237, 2016.

[14] E. Santi, A. Monti, D. Li, K. Proddutur, and R. Dougal, "Synergetic control for dc-dc boost converter: implementation options," IEEE Transactions on Industry Applications, vol. 39, no. 6, pp. 1803-1813, 2003.

[15] Z. Jiang and R. Dougal, "Synergetic control of power converters for pulse current charging of advanced batteries from a fuel cell power source," IEEE Transactions on Power Electronics, vol. 19, no. 4, pp. 1140-1150, 2004.

[16] MathWorks, abc to $d q 0, d q 0$ to $a b c$, MathWorks, Natick, MA 01760-2098, USA, 2015, http://www.mathworks.com/help/ physmod/sps/powersys/ref/abctodq0dq0toabc.html.

[17] Grid Code High and Extra High Voltage, E.ON Netz GmbH, Bayreuth, Germany, 2006.

[18] BDEW, Technical Guideline: Generating Plants Connected to the Medium-Voltage Network, BDEW, Berlin, Germany, 2008, http://www.bdew.de.

[19] DEIF, LVRT Capability-Test Results, http://www.deifwindpower. com/wind-turbine-solutions/control-systems/lvrt-test-results.

[20] H. Chong, R. Li, and B. Jim, "Unbalanced-grid-fault ridethrough control for a wind turbine inverter," IEEE Transactions on Industry Applications, vol. 44, no. 3, pp. 845-856, 2008. 

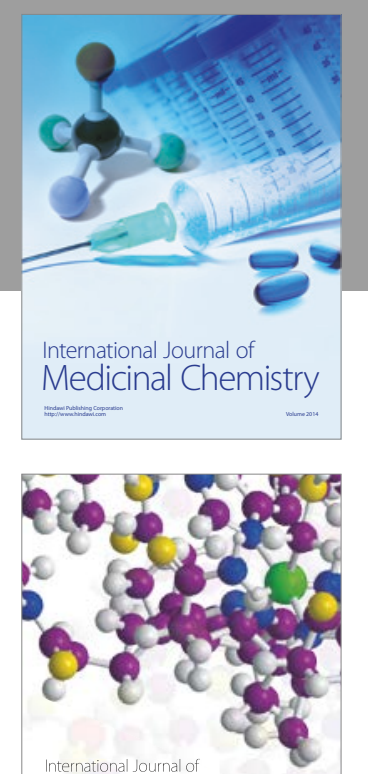

Carbohydrate Chemistry

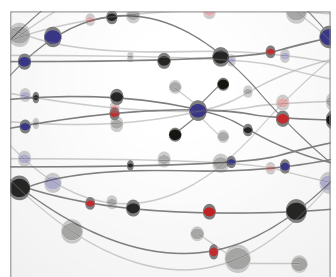

The Scientific World Journal
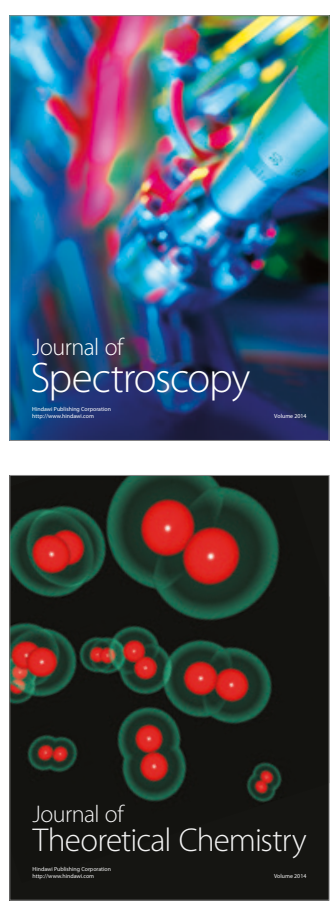
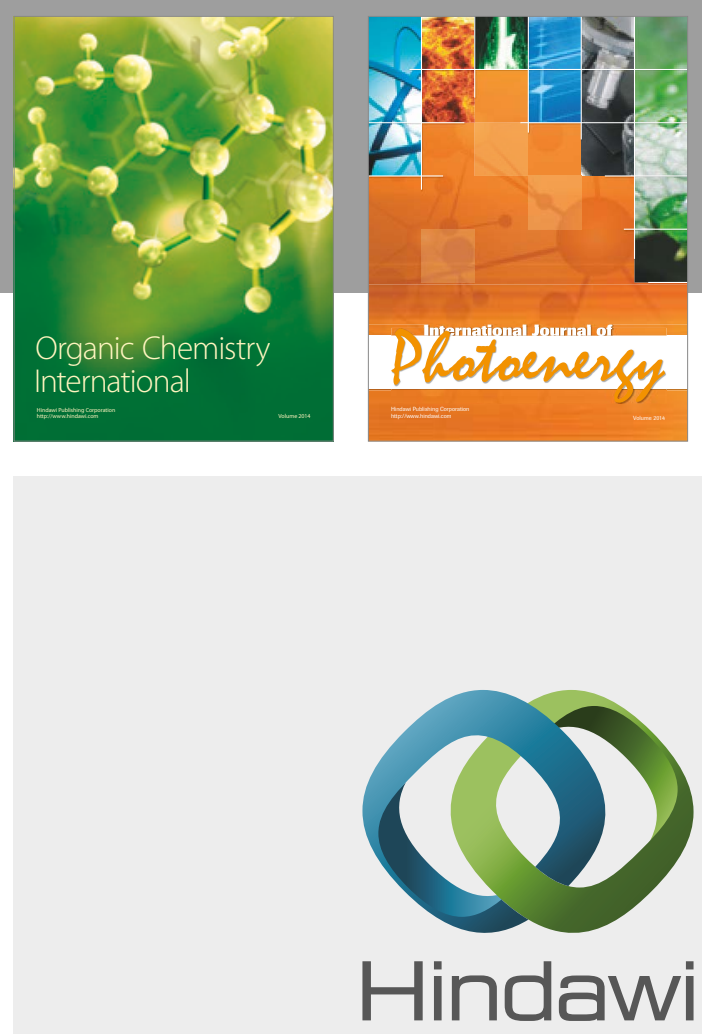

Submit your manuscripts at

https://www.hindawi.com

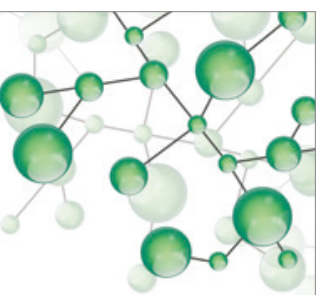

International Journal of

Inorganic Chemistry

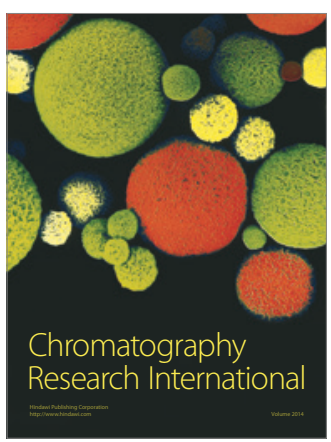

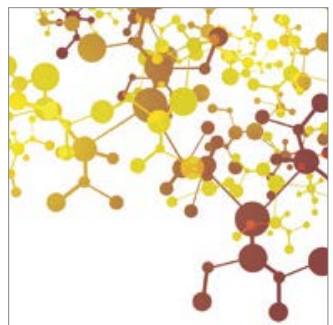

Applied Chemistry
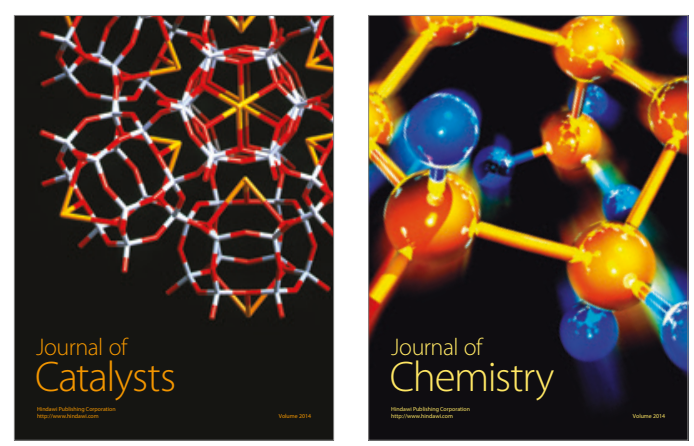
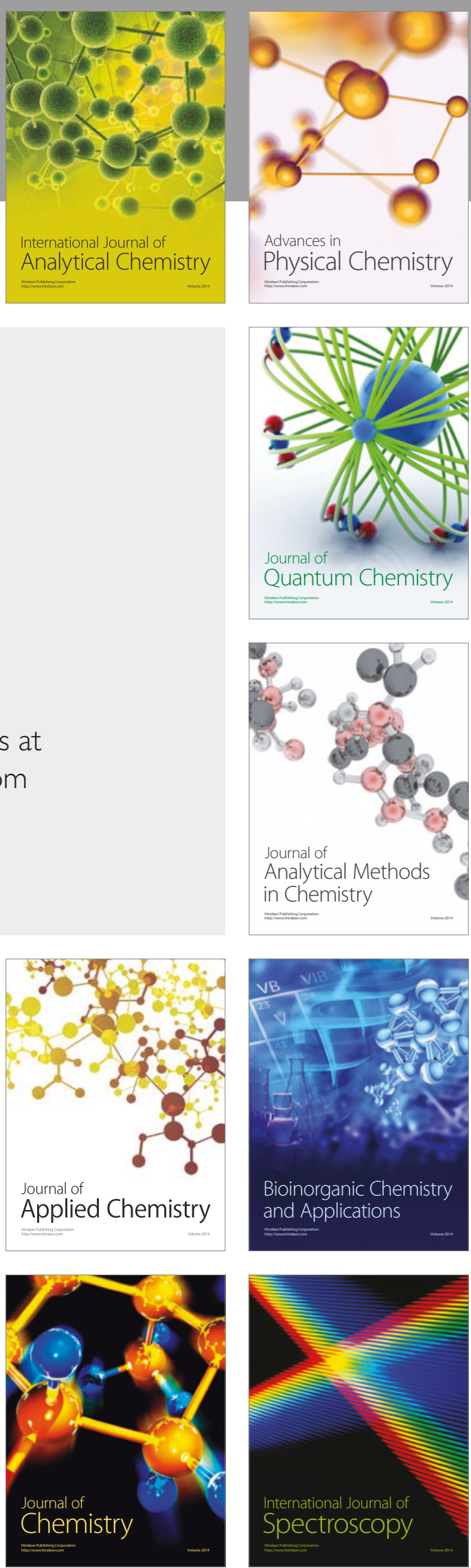